\title{
Two Patients With Resistant Immune Thrombocytopenic Purpura and Portal Hypertension Treated Safely With Laparoscopic Splenectomy: A Case Series Report and Literature Review
}

\author{
Mujtaba Mohamed ${ }^{\mathrm{a}, \mathrm{b}}$, Alsadiq Alhillan ${ }^{\mathrm{a}}$, Ishan Patel ${ }^{\mathrm{a}}$, Arman Mushtaq ${ }^{\mathrm{a}}$, \\ Eugene Zurkovsky ${ }^{a}$, Christian Kaunzinger ${ }^{\mathrm{a}}$, Mohammad A. Hossain ${ }^{\mathrm{a}}$
}

\begin{abstract}
Immune thrombocytopenia (previously called idiopathic thrombocytopenic purpura (ITP)) is characterized by an autoimmune destruction and clearance of platelets and megakaryocytes by reticuloendothelial system including liver and spleen. Most of the time, it occurs in the absence of any obvious stimulus. Secondary immune thrombocytopenia coexists with an underlying disease such as human immunodeficiency virus (HIV), hepatitis C virus (HCV), chronic lymphocytic leukemia (CLL), systemic lupus erythematosus (SLE), or can occur following exposure to certain drugs such as heparin or quinidine. Medical treatment includes corticosteroids, intravenous immunoglobulins and rituximab. Splenectomy is reserved for patients who fail medical therapy. Laparoscopic splenectomy is safer than open splenectomy. The main surgical complication of splenectomy is intraabdominal bleeding. Additional risk factors for post-operative bleeding such as portal hypertension can alter treatment decision in regard to splenectomy.
\end{abstract}

Keywords: ITP; Portal hypertension; Splenectomy

\section{Introduction}

Primary immune thrombocytopenia (previously called idiopathic thrombocytopenic purpura (ITP)) is an autoimmune disorder in which thrombocytopenia is caused by both increased peripheral platelet destruction and reduced bone marrow platelet production. ITP is a diagnosis of exclusion and

Manuscript submitted November 21, 2019, accepted November 30, 2019

${ }^{a}$ Department of Medicine, Jersey Shore University Medical Center, Hackensack Meridian Health, Neptune, NJ 07753, USA

${ }^{\mathrm{b}}$ Corresponding Author: Mujtaba Mohamed, Internal Medicine Residency Program, Jersey Shore University Medical Center, Hackensack Meridian Health, Neptune, NJ 07753, USA.

Email: Mujtaba.Mohamed@hackensackmeridian.org

doi: https://doi.org/10.14740/jcs399 there is no laboratory test to confirm the diagnosis. In most cases, platelets destruction is mediated by immunoglobulin $\mathrm{G}$ $(\mathrm{IgG})$ antibodies against platelets membrane glycoprotein. Circulating antibody-coated platelets are cleared by mononuclear phagocytic mass present in the spleen, liver and bone marrow. Corticosteroids are the standard first-line therapy of ITP, with durable response of $20-30 \%[1,2]$. Splenectomy was the standard treatment for ITP prior to the introduction of glucocorticoids more than 50 years ago. Currently, splenectomy is reserved for ITP resistant to steroids and rituximab. Bleeding is the most fearful complication especially if patient has additional risk factors. Intra-abdominal bleeding with ischemic stroke was the cause of death of one of three patients who died with laparoscopic splenectomy [3]. Herein, we are presenting two cases of resistant ITP and portal hypertension secondary to liver cirrhosis, who were treated with laparoscopic splenectomy. Both patients did not experience post-operative bleeding. One patient achieved remission without relapse. The second patient relapsed 2 months after splenectomy.

\section{Case Reports}

\section{Case 1}

Our patient is a 52-year-old woman with past medical history of human immunodeficiency virus (HIV) on highly active antiretroviral therapy (HAART) with cluster of differentiation (CD)4 of 231(381 - 1,469), untreated hepatitis C virus (HCV), compensated liver cirrhosis, portal hypertension, and immune thrombocytopenic purpura for 6 years. Patient had multiple admissions for ITP exacerbations. She was managed on those admissions with intravenous immunoglobulins (IVIGs) and steroids. Patient presented with acute onset of burgundy bowel movements (five times) and hematemesis (three times) for 12 h. She had two syncopal episodes at home. Physical examination revealed vitals: blood pressure $88 / 54 \mathrm{~mm} \mathrm{Hg}$, pulse $117 /$ min, pulse oximeter $97 \%$ on room air. The patient is pale. No rash or petechiae noted, with rectal exam positive for blood. Abdominal exam revealed no hepatomegaly, but there was splenomegaly $2 \mathrm{~cm}$ below left costal margin. Chest was clear 
to auscultation bilaterally. Heart sound S1 and S2 are within normal limits and there were no rubs, gallops or murmurs.

\section{Investigations}

Laboratory data showed: hemoglobin $10.3 \mathrm{~g} / \mathrm{dL}$ (baseline is $12-13 \mathrm{~g} / \mathrm{dL}$ ) (normal range: $12-17.5 \mathrm{~g} / \mathrm{dL}$ ), hematocrit $31 \%$ (36-53\%), white blood cell count $8.7 \times 10^{3} / \mu \mathrm{L}\left(4.5-11 \times 10^{3} /\right.$ $\mu \mathrm{L})$, and platelets count $12 \times 10^{3} / \mu \mathrm{L}\left(140-450 \times 10^{3} / \mu \mathrm{L}\right)$; sodium $139 \mathrm{mmol} / \mathrm{L}(136-145 \mathrm{mmol} / \mathrm{L})$, potassium $3.6 \mathrm{mmol} / \mathrm{L}$ (3.5 - $5.2 \mathrm{mmol} / \mathrm{L})$, chloride $108 \mathrm{mmol} / \mathrm{L}$ (96 - $110 \mathrm{mmol} / \mathrm{L})$, bicarbonate $22 \mathrm{mmol} / \mathrm{L}(24-31 \mathrm{mmol} / \mathrm{L})$, creatinine $1.07 \mathrm{mg}$ / $\mathrm{dL}(0.44-1.0 \mathrm{mg} / \mathrm{dL})$, and blood urea nitrogen (BUN) $22 \mathrm{mg} /$ $\mathrm{dL}(5$ - $25 \mathrm{mg} / \mathrm{dL})$.

\section{Differential diagnosis}

ITP flare, thrombocytopenia due to peripheral destruction by enlarged spleen, thrombocytopenia due to HIV.

\section{Treatment}

Patient was resuscitated with intravenous normal saline and transfused with two units of packed red blood cells. She had an emergency upper gastrointestinal (GI) endoscopy which revealed hemorrhagic gastritis and duodenitis, which were related to chronic steroids use for ITP. As well patient received a total of eight units of packed blood cells, IVIGs, intravenous steroids; then the platelets count increased from 12 to 50. After patient was stabilized, treatment options for refractory ITP were Rituxan versus splenectomy. Due to long time needed for Rituxan to have clinical effect ( 6 - 8 weeks), given the acuity of patient's condition due to GI bleed, patient's medical history including $\mathrm{HCV}$ and $\mathrm{HIV}$, and the concern of reactivating $\mathrm{HCV}$, Rituxan was excluded. Surgical evaluation was done. Patient received $\mathrm{H} 1 \mathrm{~B}$ and pneumococcal vaccine, and underwent laparoscopic splenectomy without complications.

\section{Outcome and follow-up}

Two weeks post-operatively, the platelets reached to $240 \times$ $10^{3} / \mu \mathrm{L}\left(140-450 \times 10^{3} / \mu \mathrm{L}\right)$, and she maintained remission for 4 years after splenectomy.

\section{Case 2}

The patient is an 86-year-old female with past medical history of ITP for 3 years, and with multiple admissions due to GI bleed secondary to low platelets. Patient received IVIGs and steroids for prior ITP exacerbations. She was recently started on Rituxan. She also has history of chronic lymphocytic leukemia (CLL) in remission and hepatitis $\mathrm{C}$ infection, which is cured by Harvoni, and compensated liver cirrhosis with portal hypertension. While at outpatient oncology, the patient was noted to have a platelet count of $9 \times 10^{3} / \mu \mathrm{L}\left(140-450 \times 10^{3} /\right.$ $\mu L)$. Patient was admitted to the medical oncology floor for further management of the ITP with IVIG. Patient's vital signs are: blood pressure $135 / 68 \mathrm{~mm} \mathrm{Hg}$, pulse $72 / \mathrm{min}$, respirations $18 / \mathrm{min}$, temperature $36.6{ }^{\circ} \mathrm{C}$, pulse oximeter $99 \%$ on room air. Chest was clear to auscultation bilaterally. Cardiovascular exam revealed normal $\mathrm{S} 1$ and $\mathrm{S} 2$, no murmur or gallop. On abdominal examination there is no hepatosplenomegaly, and non-tender. No rash or petechiae was noticed.

\section{Investigations}

Laboratory data revealed that: sodium $135 \mathrm{mmol} / \mathrm{L}$ (136 - 145 $\mathrm{mmol} / \mathrm{L})$, potassium $3.6 \mathrm{mmol} / \mathrm{L}$ (3.5 - $5.2 \mathrm{mmol} / \mathrm{L})$, chloride $102 \mathrm{mmol} / \mathrm{L}(96-110 \mathrm{mmol} / \mathrm{L})$, bicarbonate $23 \mathrm{mmol} / \mathrm{L}(24$ - $31 \mathrm{mmol} / \mathrm{L})$, BUN $9 \mathrm{mg} / \mathrm{dL}(5-25 \mathrm{mg} / \mathrm{dL})$, creatinine 0.81 $\mathrm{mg} / \mathrm{dL}(0.44-1.0 \mathrm{mg} / \mathrm{dL})$, glucose 162 . Complete blood count $(\mathrm{CBC})$ results showed: white blood cell count $3.7 \times 10^{3} / \mu \mathrm{L}$ $\left(4.5-11 \times 10^{3} / \mu \mathrm{L}\right)$, hemoglobin is $10.3 \mathrm{~g} / \mathrm{dL}(12-17.5 \mathrm{~g} / \mathrm{dL})$, hematocrit $31.1 \%(36-53 \%)$, platelets $9 \times 10^{3} / \mu \mathrm{L}(140-450 \times$ $\left.10^{3} / \mu \mathrm{L}\right)$. The international normalized ratio (INR) is $1.20(2-3$ conventional anticoagulation).

\section{Treatment}

Patient received intravenous steroids and IVIGs. Splenectomy was deemed necessary secondary to resistant ITP that did not respond to IVIG, steroids, or Rituxan. Patient received meningococcal and pneumococcal vaccine. Eventually the patient had laparoscopic splenectomy without any complication.

\section{Outcome and follow-up}

Patient achieved normal platelets count within 2 days; however she relapsed 2 months later.

\section{Discussion}

Immune thrombocytopenic purpura also known as ITP, is an immune-mediated acquired disease of adults and children characterized by transient or persistent decrease of the platelet count $<100,000$ in absence of other disorders associated with thrombocytopenia [4], and depending upon the degree of thrombocytopenia, increases risk of bleeding [5]. The incidence rates of immune thrombocytopenic purpura are between 1.1 and 12.5 per 100,000 children/year in children $[6,7]$, and between 1.6 and 3.9 per 100,000 adult/year in adults $[8,9]$. It has an acute course in children, usually occurring following acute viral infection, and most of the times it is self-limited. On the other hand, it has a chronic course in adult patients. It is twice common in women as in men [10]. ITP can be classified to either primary or secondary ITP. Primary ITP has no clear underlying etiology, and it is a diagnosis of exclusion. It 
represents $63 \%$ of cases [11]. Secondary ITP is linked to hepatitis C (10\%), Helicobacter pylori infection (5\%), HIV (3\%), systemic lupus erythematosus (SLE) (3\%), immunodeficiency states (IgA deficiency and common variable hypogammaglobulinemia), lymphoproliferative disorders (CLL, large granular lymphocytic leukemia, and lymphoma (3\%)), and drugs such as heparin and quinidine [10-14]. Distinction between primary and secondary ITP is important. Secondary ITP can be treated with treating underlying disorder whether it is autoimmune disorder, infection or a medication [15].

Many cross-sectional studies have found association of ITP with HCV. Rajan et al reported $30 \%$ of patients with HCV infection had ITP [16]. Study done by Chiao and colleagues calculated the incidence of ITP among HCV-infected and matched HCV-uninfected US veterans who received diagnoses of ITP during the period of 1997 to 2004. There was an elevated risk of developing ITP (hazard ratio, 1.8; 95\% confidence interval, 1.4 - 2.3) among both HCV-untreated and HCV treated patients [17]. Both patients we are reporting have HCV infection, and completed treatment for HCV. The association between ITP and the acquired immune deficiency syndrome was first described in 1982 by Morris et al [18]. Before the use of HAART, HIV-associated thrombocytopenia was identified in approximately 5-30\% of HIV-1-infected patients [19]. Study done by Ambler et al [20] in the HAART era showed that the incidence of thrombocytopenia in HIV-infected individuals at $26 \%$, which was similar to the incidence in preHAART era. The first patient we are reporting had HIV infection on HAART. Study done by Zent et al [21] showed CLL is associated with various autoimmune cytopenias. Of those autoimmune cytopenias, ITP has prevalence rate of $2 \%$.

ITP can be classified into newly diagnosed ITP within 3 months from diagnosis, persistent ITP between 3 to 12 months from diagnosis; and it includes patients not reaching spontaneous remission or not maintaining complete response (CR) off therapy. Chronic ITP lasts for more than 12 months. Severe ITP is defined as the presence of bleeding symptoms at presentation sufficient to mandate treatment, or occurrence of new bleeding symptoms requiring additional therapeutic intervention with a different platelet-enhancing agent or an increased dose [4].

Clinical presentation includes symptoms of low platelets count (petechiae, ecchymosis, purpura or conjunctival hemorrhage and GI bleed). Family history is usually unremarkable; careful history taking including new medications, substance use, and presence of infections or autoimmune disorders is important [10, 12-14]. Our first patient presented with lower GI bleeding and the second patient was completely asymptomatic. Massive splenomegaly should trigger suspicion for an alternative diagnosis. The first patient had mild splenomegaly, but that is because of portal hypertension. Inspection of a peripheral blood smear is required to rule out pseudothrombocytopenia or inherited giant platelet syndromes, and other hematologic disorders. Large, immature platelets (megathrombocytes) are often seen in ITP, but are not required for the diagnosis [10].

The first-line treatment for ITP is corticosteroids (prednisone $1-1.5 \mathrm{mg} / \mathrm{kg}$ body weight). The response rate is 50 $75 \%$. Response depends on intensity and duration of treatment [22]. CR is defined as any platelet count of at least $100-109$ $\times 10^{3} / \mu \mathrm{L}$. Response is defined as any platelet count between
$30-100 \times 10^{3} / \mu \mathrm{L}$ and at least doubling of the baseline count. The definition of response requires concurrent resolution of bleeding symptoms. No response (NR) is defined as any platelet count lower than $30 \times 10^{3} / \mu \mathrm{L}$ or less than doubling of the baseline count [4].

IVIG is a generally safe and effective therapy for ITP. However, they are given according to specific indications. Active bleeding (17\%) is the most common indication. Other indications include pregnancy and delivery $(16 \%)$, pre-procedure $(12 \%)$, inability to receive steroids $(9 \%)$, platelets count less than $10 \times 10^{3} / \mu \mathrm{L}(3 \%)$ and previous history of severe bleeding (1\%) [11]. Both patients we presented here received IVIG due to GI bleeding. According to Liu et al, $29 \%$ of the administrations of IVIG led to a CR, 32\% to a partial response and $39 \%$ to NR. The most commonly used dose is $1 \mathrm{~g} / \mathrm{kg}$ body weight [11]. The second-line treatment for ITP is controversial [23]. Meta-analysis of 31 studies done by Arnold et al about the efficacy and safety of rituximab for adults with ITP showed CR of $46.3 \%$ (based on 13 studies) after treatment with rituximab [24]. A partial response was observed in 24\% (16 studies), an overall response (more than $50 \times 10^{3} / \mu \mathrm{L}$ platelets) was reported for $62.5 \%$ (19 studies) [24]. The median time to response was 5.5 weeks (interquartile range: $3.0,6.6$; six studies) from the first dose of rituximab. The median response duration was 10.5 months (interquartile range: 6.3, 17.8; 16 studies). Sixty-six patients $(22 \%)$ in 29 studies showed a mild to moderate adverse event, majority being infusion reactions. Ten patients (4\%) experienced severe or life-threatening events and nine patients (3\%) died. Relapses are frequent with rituximab therapy with long-term response rate at 12 and 24 months $(40 \%$ and $33 \%$, respectively) $[25,26]$. Our first patient did not receive rituximab due to acuity of her condition (GI bleed) and the amount of time required for rituximab effect to start ( $5-6$ weeks). The second patient failed rituximab therapy. There is evidence that some patients can be started on IVIG maintenance therapy after failing all other options. This approach is safe and associated with less side effects than chronic corticosteroids [27]. However, this approach is not cost-effective and should be reserved to patients who exhausted all other therapeutic modalities [28]. Our second patient who relapsed after splenectomy was not started on maintenance immunoglobulin therapy.

Splenectomy is the second-line therapy for ITP not responsive to medical treatment. Numerous studies indicated about $66 \%$ of patients have response within days [29]. Our first patient achieved CR within 2 weeks after splenectomy with the platelet count of $240 \times 10^{3} / \mu \mathrm{L}$ (normal range: $140-450 \times 10^{3} /$ $\mu \mathrm{L})$. The second patient achieved normal counts within 2 days post-operatively with platelet count of $153 \times 10^{3} / \mu \mathrm{L}$. However, there is no way to predict individual response to splenectomy. Prognostic factors for success of splenectomy are age and duration of ITP. The mean age at the time of splenectomy for responding patients was 30.31 years, compared with 58.00 years in non-responding patients. The analysis of age response frequency distributions showed the cut-off to be 52 years of age. All nonresponsive patients were over the age of 52 years, whereas all responsive patients were in under-52-year age range. Our first patient was 52 years of age at the time of splenectomy, and she had an excellent and sustained response. Our second patient was 86 years, and she had a good response 
within 2 days however she relapsed in 2 months. Duration of disease among non-responding patients was significantly higher than among responding patients with 90.80 months versus 13.73 months. Our first patient was diagnosed 6 years prior to splenectomy and the second one was diagnosed 3 years before splenectomy. Duration of corticosteroid therapy was also higher among non-responding patients with 48.00 months versus 8.04 months [30]. Other good prognostic factors include previous response to steroids, previous response to high dose immunoglobulins and site of sequestration [31-33]. Chater et al mentioned on his study that at 30 months, response and CR rates are significantly different. Response rates are $93.1 \%$ for laparoscopic splenectomy, $86.5 \%$ in open splenectomy, and $46.7 \%$ for rituximab [34].

Laparoscopic splenectomy has similar long-term efficacy but less morbidity and shorter length of stay as compared to open splenectomy [35]. Laparoscopic splenectomy yielded less Clavien-Dindo grade I complications reported as $10.5 \%$ versus $32.5 \%$ with open splenectomy. Regarding hospitalization days, laparoscopic splenectomy and open splenectomy has 5.8 versus 7.4 days, respectively. Laparoscopic splenectomy often drained (3.5\% versus $27 \%$ for open splenectomy) [35]. Intra-abdominal bleeding is the most devastating complication especially if patient has additional risk factors such as portal hypertension or other bleeding diathesis. Intra-abdominal bleeding with stroke was the cause of death of one of three patients who died with laparoscopic splenectomy [3].

To our knowledge, there was no reported case of laparoscopic splenectomy done in patients with ITP who had liver cirrhosis and portal hypertension. As portal hypertension and liver cirrhosis represent addition risk of bleeding in patients with ITP, both cases had laparoscopic splenectomy without complications.

\section{Conclusions}

Patients with additional risk factors for bleeding secondary to portal hypertension and associated comorbidities including $\mathrm{HCV}$ and HIV can safely undergo splenectomy. Laparoscopic splenectomy should be pursued without additional concerns for complications including intra-abdominal bleeding. Our case series can serve clinicians while make informed decisions with their patients in similar scenarios. Predicting factors for success of splenectomy include duration since diagnosis, age of the patient, and previous response to steroids.

\section{Acknowledgments}

We would like to thank Chunwei, Ma (Liberian at Jersey Shore University Medical Center) for the help providing us with other case reports of ITP resistant to medical therapy to compare them to our cases.

\section{Financial Disclosure}

All authors have no financial conflict of interest to declare.

\section{Conflict of Interest}

The authors declare that there is no conflict of interest regarding the publication of this paper.

\section{Informed Consent}

Written informed consent was obtained from the patient for publication of this case report.

\section{Author Contributions}

MAH, EZ, AM and CK encouraged MM, AA and IP to learn about ITP and management options. MM presented the idea, AA, MM and IP wrote the manuscript with input from all authors. Each author has individually been involved and participated in drafting the manuscript and revising it critically for important intellectual content. All authors discussed the medical literature, and have given final approval of the version to be published.

\section{References}

1. Stasi R, Evangelista ML, Stipa E, Buccisano F, Venditti A, Amadori S. Idiopathic thrombocytopenic purpura: current concepts in pathophysiology and management. Thromb Haemost. 2008;99(1):4-13.

2. Cines DB, McMillan R. Management of adult idiopathic thrombocytopenic purpura. Annu Rev Med. 2005;56:425442.

3. Kojouri K, Vesely SK, Terrell DR, George JN. Splenectomy for adult patients with idiopathic thrombocytopenic purpura: a systematic review to assess long-term platelet count responses, prediction of response, and surgical complications. Blood. 2004;104(9):2623-2634.

4. Rodeghiero F, Stasi R, Gernsheimer T, Michel M, Provan D, Arnold DM, Bussel JB, et al. Standardization of terminology, definitions and outcome criteria in immune thrombocytopenic purpura of adults and children: report from an international working group. Blood. 2009;113(11):2386-2393.

5. Cooper N, Bussel J. The pathogenesis of immune thrombocytopaenic purpura. Br J Haematol. 2006;133(4):364374.

6. Watts RG. Idiopathic thrombocytopenic purpura: a 10year natural history study at the childrens hospital of alabama. Clin Pediatr (Phila). 2004;43(8):691-702.

7. Zaki M, Hassanein AA, Khalil AF. Childhood idiopathic thrombocytopenic purpura: report of 60 cases from $\mathrm{Ku}-$ wait. J Trop Pediatr. 1990;36(1):10-13.

8. Neylon AJ, Saunders PW, Howard MR, Proctor SJ, Taylor PR, Northern Region Haematology G. Clinically significant newly presenting autoimmune thrombocytopenic purpura in adults: a prospective study of a population-based cohort of 245 patients. Br J Haematol. 
2003;122(6):966-974.

9. Abrahamson PE, Hall SA, Feudjo-Tepie M, Mitrani-Gold FS, Logie J. The incidence of idiopathic thrombocytopenic purpura among adults: a population-based study and literature review. Eur J Haematol. 2009;83(2):83-89.

10. Cines DB, Blanchette VS. Immune thrombocytopenic purpura. N Engl J Med. 2002;346(13):995-1008.

11. Liu J, Pavenski K, Sholzberg M. Appropriateness of intravenous immunoglobulin use in immune thrombocytopenia (ITP): A Canadian centre deep dive audit. Transfus Apher Sci. 2019;58(4):491-494.

12. Stasi R, Willis F, Shannon MS, Gordon-Smith EC. Infectious causes of chronic immune thrombocytopenia. Hematol Oncol Clin North Am. 2009;23(6):1275-1297.

13. Fujimura K. Helicobacter pylori infection and idiopathic thrombocytopenic purpura. Int J Hematol. 2005;81(2):113-118.

14. Pockros PJ, Duchini A, McMillan R, Nyberg LM, McHutchison J, Viernes E. Immune thrombocytopenic purpura in patients with chronic hepatitis $\mathrm{C}$ virus infection. Am J Gastroenterol. 2002;97(8):2040-2045.

15. Visco C, Ruggeri M, Laura Evangelista M, Stasi R, Zanotti R, Giaretta I, Ambrosetti A, et al. Impact of immune thrombocytopenia on the clinical course of chronic lymphocytic leukemia. Blood. 2008;111(3):1110-1116.

16. Rajan SK, Espina BM, Liebman HA. Hepatitis C virusrelated thrombocytopenia: clinical and laboratory characteristics compared with chronic immune thrombocytopenic purpura. Br J Haematol. 2005;129(6):818-824.

17. Chiao EY, Engels EA, Kramer JR, Pietz K, Henderson L, Giordano TP, Landgren O. Risk of immune thrombocytopenic purpura and autoimmune hemolytic anemia among 120908 US veterans with hepatitis C virus infection. Arch Intern Med. 2009;169(4):357-363.

18. Morris L, Distenfeld A, Amorosi E, Karpatkin S. Autoimmune thrombocytopenic purpura in homosexual men. Ann Intern Med. 1982;96(6 Pt 1):714-717.

19. Stasi R. Therapeutic strategies for hepatitis- and other infection-related immune thrombocytopenias. Semin Hematol. 2009;46(1 Suppl 2):S15-25.

20. Ambler KL, Vickars LM, Leger CS, Foltz LM, Montaner JS, Harris M, Dias Lima V, et al. Clinical features, treatment, and outcome of HIV-associated immune thrombocytopenia in the HAART era. Adv Hematol. 2012;2012:910954.

21. Zent CS, Ding W, Reinalda MS, Schwager SM, Hoyer JD, Bowen DA, Jelinek DF, et al. Autoimmune cytopenia in chronic lymphocytic leukemia/small lymphocytic lymphoma: changes in clinical presentation and prognosis. Leuk Lymphoma. 2009;50(8):1261-1268.

22. den Ottolander GJ, Gratama JW, de Koning J, Brand A. Long-term follow-up study of 168 patients with immune thrombocytopenia. Implications for therapy. Scand J Haematol. 1984;32(1):101-110.

23. Provan D, Stasi R, Newland AC, Blanchette VS, Bolton-Maggs $\mathrm{P}$, Bussel JB, Chong $\mathrm{BH}$, et al. International consensus report on the investigation and management of primary immune thrombocytopenia. Blood.
2010;115(2):168-186.

24. Arnold DM, Dentali F, Crowther MA, Meyer RM, Cook RJ, Sigouin C, Fraser GA, et al. Systematic review: efficacy and safety of rituximab for adults with idiopathic thrombocytopenic purpura. Ann Intern Med. 2007;146(1):25-33.

25. Godeau B, Porcher R, Fain O, Lefrere F, Fenaux P, Cheze $\mathrm{S}$, Vekhoff A, et al. Rituximab efficacy and safety in adult splenectomy candidates with chronic immune thrombocytopenic purpura: results of a prospective multicenter phase 2 study. Blood. 2008;112(4):999-1004.

26. Patel VL, Mahevas M, Lee SY, Stasi R, Cunningham-Rundles S, Godeau B, Kanter J, et al. Outcomes 5 years after response to rituximab therapy in children and adults with immune thrombocytopenia. Blood. 2012;119(25):59895995.

27. Bussel JB, Pham LC, Aledort L, Nachman R. Maintenance treatment of adults with chronic refractory immune thrombocytopenic purpura using repeated intravenous infusions of gammaglobulin. Blood. 1988;72(1):121-127.

28. Xie F, Blackhouse G, Assasi N, Campbell K, Levin M, Bowen J, Tarride JE, et al. Results of a model analysis to estimate cost utility and value of information for intravenous immunoglobulin in Canadian adults with chronic immune thrombocytopenic purpura. Clin Ther. 2009;31(5):1082-1091; discussion 1066-1088.

29. George JN, Woolf SH, Raskob GE, Wasser JS, Aledort LM, Ballem PJ, Blanchette VS, et al. Idiopathic thrombocytopenic purpura: a practice guideline developed by explicit methods for the American Society of Hematology. Blood. 1996;88(1):3-40.

30. Shojaiefard A, Mousavi SA, Faghihi SH, Abdollahzade S. Prediction of response to splenectomy in patients with idiopathic thrombocytopenic purpura. World J Surg. 2008;32(3):488-493.

31. Zimmer J, Andres E, Noel E, Koumarianou A, Blickle JF, Maloisel F. Current management of adult idiopathic thrombocytopenic purpura in practice: a cohort study of 201 patients from a single center. Clin Lab Haematol. 2004;26(2):137-142.

32. Choi CW, Kim BS, Seo JH, Shin SW, Kim YH, Kim JS, Sohn SK, et al. Response to high-dose intravenous immune globulin as a valuable factor predicting the effect of splenectomy in chronic idiopathic thrombocytopenic purpura patients. Am J Hematol. 2001;66(3):197-202.

33. Kinuya K, Matano S, Nakashima H, Taki S. Scintigraphic prediction of therapeutic outcomes of splenectomy in patients with thrombocytopenia. Ann Nucl Med. 2003;17(2):161-164.

34. Chater C, Terriou L, Duhamel A, Launay D, Chambon JP, Pruvot FR, Rogosnitzky M, et al. Reemergence of Splenectomy for ITP Second-line Treatment? Ann Surg. 2016;264(5):772-777.

35. Cordera F, Long KH, Nagorney DM, McMurtry EK, Schleck C, Ilstrup D, Donohue JH. Open versus laparoscopic splenectomy for idiopathic thrombocytopenic purpura: clinical and economic analysis. Surgery. $2003 ; 134(1): 45-52$. 